\title{
R620W functional polymorphism of protein tyrosine phosphatase non-receptor type 22 is not associated with pulmonary tuberculosis in Zahedan, southeast Iran
}

\author{
H.-R. Kouhpayeh ${ }^{1}$, M. Hashemi ${ }^{2,3}$, S.-A. Hashemi ${ }^{1}$, A. Moazeni-Roodi ${ }^{1}$, \\ M. Naderi ${ }^{1}$, B. Sharifi-Mood ${ }^{1}$, M. Taheri ${ }^{2}$, M. Mohammadi ${ }^{4}$ and S. Ghavami ${ }^{5}$ \\ ${ }^{1}$ Research Center for Infectious Diseases and Tropical Medicine, \\ Zahedan University of Medical Sciences, Zahedan, Iran \\ ${ }^{2}$ Cellular and Molecular Research Center, \\ Zahedan University of Medical Sciences, Zahedan, Iran \\ ${ }^{3}$ Department of Clinical Biochemistry, School of Medicine, \\ Zahedan University of Medical Sciences, Zahedan, Iran \\ ${ }^{4}$ Health Promotion Research Center, \\ Zahedan University of Medical Sciences, Zahedan, Iran \\ ${ }^{5}$ Department of Physiology, Manitoba Institute of Child Health, \\ University of Manitoba, Winnipeg, Manitoba, Canada \\ Corresponding author: M. Hashemi \\ E-mail: mhd.hashemi@gmail.com
}

Genet. Mol. Res. 11 (2): 1075-1081 (2012)

Received July 19, 2011

Accepted December 16, 2011

Published April 27, 2012

DOI http://dx.doi.org/10.4238/2012.April.27.6

\begin{abstract}
The protein tyrosine phosphatase non-receptor type 22 (PTPN22) gene, which encodes an intracellular lymphoid-specific phosphatase, is considered an important regulator of T-cell activation. We investigated a possible association between the PTPN22 C1858T (R620W) polymorphism and pulmonary tuberculosis in an Iranian population. Single nucleotide polymorphisms of PTPN22 C1858T (rs2476601) were genotyped in 172 pulmonary tuberculosis cases and 204 normal subjects from Zaheden, Iran. Frequencies of genotypes CC,
\end{abstract}


CT and TT of the PTPN22 C1858T polymorphism were 98.3, 1.7 and $0 \%$ in the pulmonary tuberculosis patients, and $96.1,3.9$ and $0 \%$ in the control group, respectively $(\mathrm{P}=0.239)$. The frequency of the minor (T) allele was $0.8 \%$ in pulmonary tuberculosis patients and $2.0 \%$ in controls. Significant differences were not observed in genotype or allele frequencies of PTPN22 C1858T in the comparison between pulmonary tuberculosis patients and healthy subjects in our Iranian population sample.

Key words: PTPN22; Tuberculosis; Polymorphism

\section{INTRODUCTION}

Pulmonary tuberculosis (PTB) is still a major health problem worldwide, and it remains the main cause of morbidity and mortality (Naderi et al., 2009, 2010). It has been known that over one-third of the world's population is infected with Mycobacterium tuberculosis, of whom only 10\% develop the clinical disease (Porter and McAdam, 1994). Persuasive evidence from twin studies indicates that host genetic factors are significant risk factors for development of tuberculosis (Comstock, 1978). The findings of numerous diverse tuberculosis (TB) susceptibility genes in genome-wide screens supported the possibility of multigenic predisposition to TB (Bellamy et al., 2000; Cervino et al., 2002). The lung is the main target of infection with $M$. tuberculosis. It is well-known that in most subjects infected with $M$. tuberculosis, host immunity responses effectively control the infection (North and Jung, 2004).

The PTPN22 gene is located on chromosome 1p13.3-p13.1 and encodes intracellular lymphoid tyrosine phosphatase (LYP) (Cohen et al., 1999). LYP, which is expressed only in cells of hematopoietic origin, dephosphorylates kinases such as Lck, Fyn, and Zap-70, all of them recognized to be important in T-cell signaling (Mustelin et al., 1999). It has been documented that dephosphorylation of these substrates by LYP negatively modulates T-cell activation (Hermiston et al., 2002; Mustelin et al., 2002; Veillette et al., 2002). In addition, LYP binds to the adaptor molecule Grb2 (growth factor receptor-bound protein 2), and this interaction is thought to play a negative regulatory function in T-cell signaling (Hill et al., 2002). Moreover, LYP binds to the C-terminus of Src tyrosine kinase (Csk) and downregulates the activation of T cells. Csk is a key suppressor of kinases that mediate T-cell activation (Cohen et al., 1999). It has been reported that the PTPN22 C1858T (R620W) polymorphism placed at the P1 motif does not bind Csk, preventing formation of the complex and, consequently, suppression of T-cell activation (Bottini et al., 2004).

Several studies have found a significant association between a functional missense PTPN22 C1858T (R620W) polymorphism and vulnerability to numerous autoimmune diseases such as type 1 diabetes, rheumatoid arthritis and systemic lupus erythematosus (Gomez et al., 2005a; Chelala et al., 2007; Lee et al., 2007; Douroudis et al., 2008).

To the best of our knowledge, the data regarding PTPN22 C1858T polymorphism in PTB are scant (Gomez et al., 2005b; Lamsyah et al., 2009), and there is no report in our country. Thus, the aim of the present study was to find out the association between PTPN22 C1858T (R620W) polymorphism and PTB in an Iranian population. 


\section{MATERIAL AND METHODS}

This case-control study was performed from July 2008 to April 2010 in the Research Center for Infectious Diseases and Tropical Medicine, Bou-Ali Hospital, Zahedan, Iran. The project was approved by the Ethics Committee of Zahedan University of Medical Sciences, and informed consent was obtained from all patients and healthy subjects. The study consisted of 172 PTB (64 males, 108 females; mean age $50.3 \pm 20.3$ ) and 204 healthy subjects (94 males, 110 females; mean age $47.5 \pm 14.7$ ). The diagnosis of PTB was based on clinical, radiological, sputum acid fast bacillus (AFB) smear positivity, culture and response to antituberculosis chemotherapy, as previously described (Naderi et al., 2009; Hashemi et al., 2011b).

Two milliliters of venous blood was drawn from each subject, and genomic DNA was extracted from peripheral blood as previously described (Hashemi et al., 2010a).

Tetra primer ARMS-PCR is a simple and rapid method for detection of SNPs (Hashemi et al., 2010a,b, 2011a). Tetra primer ARMS-PCR was designed for the detection of PTPN22 R620W (rs2476601) polymorphism. We used two external primers (forward outer primer: 5'-CTCACACATCAGCTTCCCAAAGTG-3', reverse outer primer: 5'-CAACTT TACTGATAATGTTGCTTCAACGGA-3') and two internal primers (forward inner primer: 5'-CAACCACAATAAATGATTCAGGTGTACG-3', reverse inner primer: 5'-ATCCCCCCTC CACTTCCTGGAT-3'). Product sizes were $213 \mathrm{bp}$ for the $\mathrm{C}$ allele and $151 \mathrm{bp}$ for the $\mathrm{T}$ allele, while the product size of the two outer primers was $314 \mathrm{bp}$ as illustrated schematically in Figure 1.

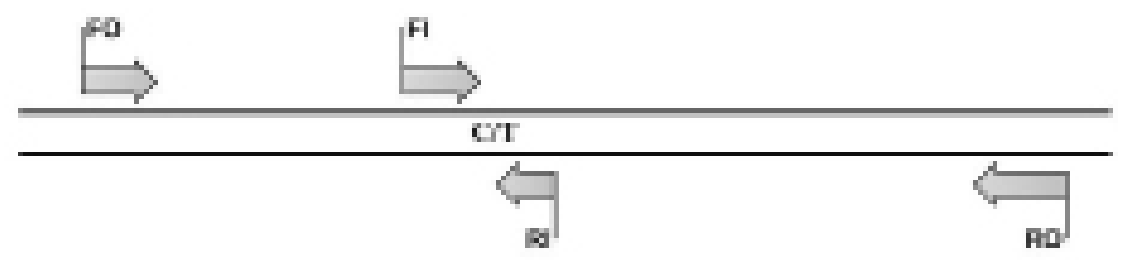

T sliki band: 15i

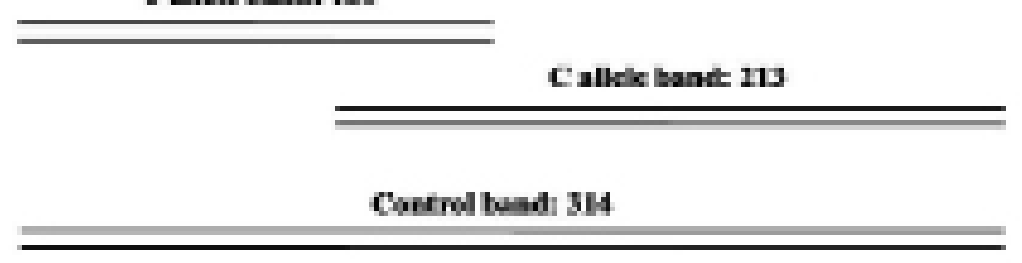

Figure 1. Schematic diagram of the tetra ARMS assay for determination of the PTPN22 C1858T polymorphism. Two forward and two reverse primers are used to generate three potential PCR products. Primers FO and RO give a 314-bp product, which is used for control of DNA quality and quantity. Primers FO and RI amplify the T allele, generating a 151-bp product, and primers FI and RO generate a 213-bp product for the C allele.

PCR was performed using commercially available PCR premix (AccuPower PCR PreMix, BIONEER, Daejeon, Korea) according to the manufacturer recommended protocol. A 0.2-mL PCR tube was used, containing the AccuPower PCR PreMix, $1 \mu \mathrm{L}$ template DNA $(\sim 100 \mathrm{ng} / \mu \mathrm{L}), 1 \mu \mathrm{L}$ of each primer $(10 \mu \mathrm{M})$ and $15 \mu \mathrm{L}$ DNase-free water. The total volume for PCR was $20 \mu \mathrm{L}$. 
PCR cycling conditions were $5 \mathrm{~min}$ at $95^{\circ} \mathrm{C}$ followed by 30 cycles of $30 \mathrm{~s}$ at $95^{\circ} \mathrm{C}$, $30 \mathrm{~s}$ at $64^{\circ} \mathrm{C}$, and $30 \mathrm{~s}$ at $72^{\circ} \mathrm{C}$, and $10 \mathrm{~min}$ at $72^{\circ} \mathrm{C}$ (Corbett Research, Australia). The PCR products were electrophoresed on 3\% agarose gels and photographed (Figure 2). To ensure genotyping quality, we regenotyped the samples at random to verify the initial results.

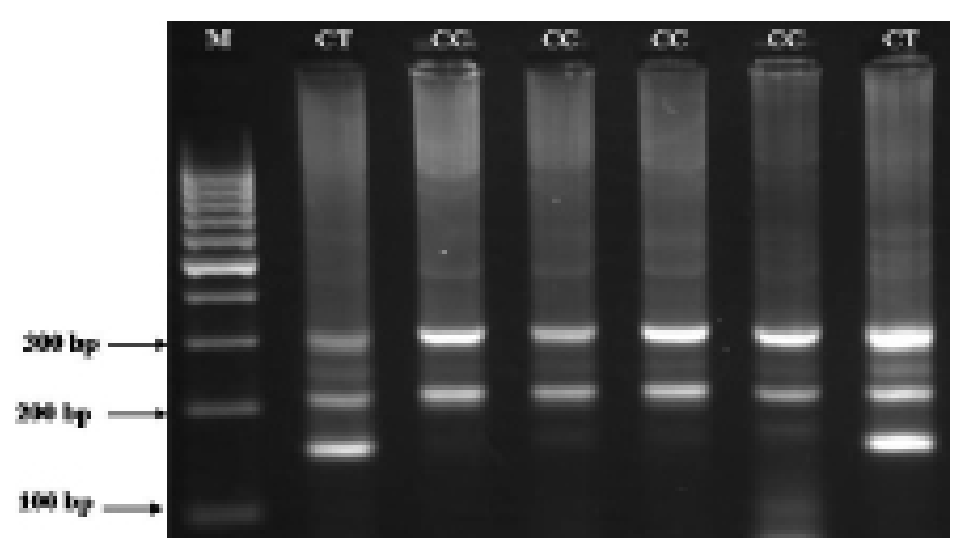

Figure 2. Results of tetra ARMS-PCR of the PTPN22 C1858T polymorphism. Lane $M=$ DNA marker.

The statistical analysis of the data was performed using the SPSS 17.0 software. Genotypes and alleles were compared between the groups using the Fisher exact test.

\section{RESULTS}

We determined the genotypic frequency of 1858 PTPN22 C/T polymorphism in PTB and control subjects (Table 1). Genotype frequencies of both patients and healthy controls satisfied the Hardy-Weinberg equilibrium. The CC genotype was observed in 98.3\% (169/172) patients, whereas $1.7 \%(3 / 172)$ were heterozygous (CT) and none of the patients had a TT genotype. In the control group, the frequencies of genotypes were $96.1 \%(196 / 204)$ for CC, $3.9 \%(8 / 204)$ for CT and $0 \%(0 / 204)$ for TT (Table 1$)$. No homozygous TT genotype was found among PTB patients or healthy subjects. There were no significant differences between case and control groups regarding PTPN22 $\mathrm{C} / \mathrm{T}$ polymorphism $(\mathrm{P}=0.239)$.

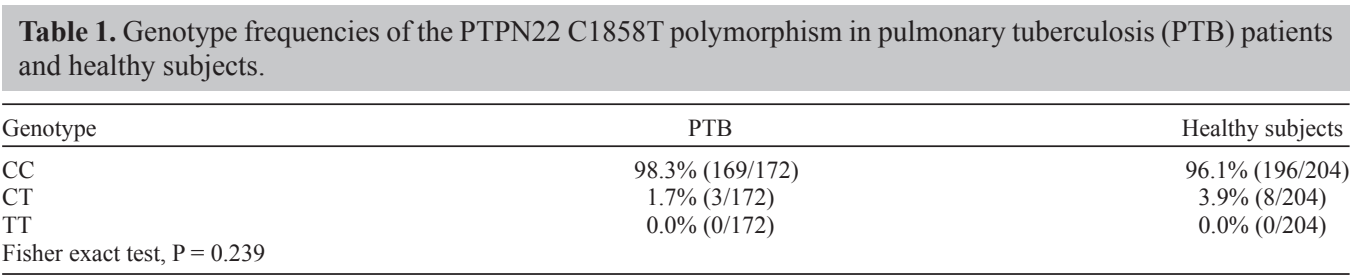

The distribution of PTPN22 C/T allele frequencies in PTB and normal individuals is shown in Table 2. No significant difference was observed between PTB and control subjects regarding allele frequencies (Fisher exact test, $\mathrm{P}=0.241$ ). 
Table 2. Allele frequencies of PTPN22 C1858T in pulmonary tuberculosis (PTB) patients and healthy subjects.

\begin{tabular}{lcc}
\hline Allele & PTB & Healthy subjects \\
\hline $\mathrm{C}$ & $99.1 \%(341 / 344)$ & $98.0 \%(400 / 408)$ \\
$\mathrm{T}$ & $0.9 \%(3 / 344)$ & $2.0 \%(8 / 408)$ \\
Fisher exact test, $\mathrm{P}=0.241$ & & \\
\hline
\end{tabular}

\section{DISCUSSION}

In the present study, we found no association between the genotypic and allelic frequencies of the PTPN22 C1858T gene polymorphism and susceptibility to PTB in a sample of the Iranian population. We did not detect individuals carrying the TT genotype among patients and controls. To date, there are only two reports regarding the association between PTPN22 polymorphisms and PTB. In contrast to our findings, Lamsyah et al. (2009) observed statistically significant differences in the PTPN22 C1858T genotypic and allelic frequencies between PTB and controls in a Moroccan population. The frequency of the minor allele (T allele) was found to be $0.41 \%$ in PTB and 3.2\% in normal subjects (Lamsyah et al., 2009). In another study, Gomez et al. (2005b) found statistically significant differences in the PTPN22 C1858T genotypic and allelic frequencies between PTB and controls in a Columbian population. The frequency of the T allele was found to be $1.3 \%$ in PTB and $4.3 \%$ in normal subjects. The distribution of $\mathrm{T}$ allele frequencies in our study is in accordance with these findings (Gomez et al., 2005b; Lamsyah et al., 2009). The finding of no homozygous TT individuals among PTB patients or healthy controls in our study is in line with the findings of Lamsyah et al. (2009) and Gomez et al. (2005b) in a Moroccan and Colombian population, respectively. These studies suggest a potential protective role of the $\mathrm{T}$ allele in TB. Our results are in disagreement with these findings and this discrepancy may be due to the different ethnicity of subjects participating in the studies.

It has been reported that the PTPN22 C1858T polymorphism is not involved in vulnerability to Brucella melitensis, an intracellular pathogen, which gives rise to human brucellosis (Bravo et al., 2009). Several studies have found a significant association between the PTPN22 C1858T (R620W) polymorphism and vulnerability to various autoimmune diseases (Gomez et al., 2005a; Chelala et al., 2007; Lee et al., 2007; Douroudis et al., 2008).

In the majority of infected subjects, active natural and acquired immune responses successfully control M. tuberculosis. The exact reasons as to why only a number of the individuals infected with $M$. tuberculosis develop clinical disease remain unknown. There is some evidence that suggests that host genetic factors may be important risk factors for the development of tuberculosis (Guide and Holland, 2002; Hashemi et al., 2011b; Qu et al., 2011).

Variation in allele frequency of the PTPN22 C1858T (R620W) has been reported among different ethnic populations. The highest frequency of the minor allele (T allele) has been observed in Scandinavian countries [12.3\% in Sweden (Reddy et al., 2005) and 15.5\% in Finland (Seldin et al., 2005)]. Minor allele frequencies in Western Europe have ranged from 7 to 10\% [Spain, 7-7.4\% (Orozco et al., 2005); France, 9.2\% (Wipff et al., 2006); Germany, 10\% (Jagiello et al., 2005); UK, 10.3\% (Hinks et al., 2006), and Italy, 2.1\% (Bottini et al., 2004)]. The C1858T SNP is considerably less polymorphic in non-Caucasian populations such as Colombian (4.3\%) and Moroccan populations (3.22\%) (Gomez et al., 2005b; Lamsyah et al., 2009). Actually, this polymorphism has not been found in African or Asian populations 
(Begovich et al., 2004; Ban et al., 2005; Mori et al., 2005; Chabchoub et al., 2006; Ikegami et al., 2007; Chabchoub et al., 2009). The frequency of the PTPN22-1858T allele in a Chinese population was found to be $1.43 \%$ (Zhang et al., 2008). To the best of our knowledge, for the first time, we found a low frequency of the minor allele (T allele frequency of $0.8 \%$ in PTB and $2.0 \%$ in normal individuals) in a sample of Iranians, which shows that PTPN22 is less polymorphic in our population. There are few data regarding PTPN22 polymorphisms and tuberculosis. Considering the small sample size of studies, a larger sample size is required to obtain the sufficient statistical power.

In conclusion, we found that the PTPN22 C1858T (R620W) is not involved in the susceptibility to PTB in Iranian patients.

\section{ACKNOWLEDGMENTS}

Research supported by Zahedan School of Medicine through a dissertation grant. In addition, the authors would like to thank the patients and healthy subjects who willingly participated in the study.

\section{REFERENCES}

Ban Y, Tozaki T, Taniyama M and Tomita M (2005). The codon 620 single nucleotide polymorphism of the protein tyrosine phosphatase-22 gene does not contribute to autoimmune thyroid disease susceptibility in the Japanese. Thyroid 15: 1115-1118.

Begovich AB, Carlton VE, Honigberg LA, Schrodi SJ, et al. (2004). A missense single-nucleotide polymorphism in a gene encoding a protein tyrosine phosphatase (PTPN22) is associated with rheumatoid arthritis. Am. J. Hum. Genet. 75: 330-337.

Bellamy R, Beyers N, McAdam KP, Ruwende C, et al. (2000). Genetic susceptibility to tuberculosis in Africans: a genome-wide scan. Proc. Natl. Acad. Sci. U. S. A. 97: 8005-8009.

Bottini N, Musumeci L, Alonso A, Rahmouni S, et al. (2004). A functional variant of lymphoid tyrosine phosphatase is associated with type I diabetes. Nat. Genet. 36: 337-338.

Bravo MJ, Colmenero JD, Queipo-Ortuno MI, Morata P, et al. (2009). PTPN22 C1858T polymorphism and human brucellosis. Scand J. Infect. Dis. 41: 109-112.

Cervino AC, Lakiss S, Sow O, Bellamy R, et al. (2002). Fine mapping of a putative tuberculosis-susceptibility locus on chromosome 15q11-13 in African families. Hum. Mol. Genet. 11: 1599-1603.

Chabchoub G, Maalej A, Petit-Teixeira E, Glikmans E, et al. (2006). Polymorphisms in the protein tyrosine phosphatase (PTPN22) gene is not associated with autoimmune thyroid in a large affected Tunisian family. Clin. Immunol. 120: 235-236.

Chabchoub G, Teixiera EP, Maalej A, Ben HM, et al. (2009). The R620W polymorphism of the protein tyrosine phosphatase 22 gene in autoimmune thyroid diseases and rheumatoid arthritis in the Tunisian population. Ann. Hum. Biol. 36: 342-349.

Chelala C, Duchatelet S, Joffret ML, Bergholdt R, et al. (2007). PTPN22 R620W functional variant in type 1 diabetes and autoimmunity related traits. Diabetes 56: 522-526.

Cohen S, Dadi H, Shaoul E, Sharfe N, et al. (1999). Cloning and characterization of a lymphoid-specific, inducible human protein tyrosine phosphatase, Lyp. Blood 93: 2013-2024.

Comstock GW (1978). Tuberculosis in twins: a re-analysis of the Prophit survey. Am. Rev. Respir. Dis. 117: 621-624.

Douroudis K, Prans E, Haller K, Nemvalts V, et al. (2008). Protein tyrosine phosphatase non-receptor type 22 gene variants at position 1858 are associated with type 1 and type 2 diabetes in Estonian population. Tissue Antigens 72: 425-430.

Gomez LM, Anaya JM, Gonzalez CI, Pineda-Tamayo R, et al. (2005a). PTPN22 C1858T polymorphism in Colombian patients with autoimmune diseases. Genes Immun. 6: 628-631.

Gomez LM, Anaya JM and Martin J (2005b). Genetic influence of PTPN22 R620W polymorphism in tuberculosis. Hum. Immunol. 66: 1242-1247. 
Guide SV and Holland SM (2002). Host susceptibility factors in mycobacterial infection. Genetics and body morphotype. Infect. Dis. Clin. North Am. 16: 163-186.

Hashemi M, Moazeni-Roodi AK, Fazaeli A, Sandoughi M, et al. (2010a). Lack of association between paraoxonase-1 Q192R polymorphism and rheumatoid arthritis in southeast Iran. Genet. Mol. Res. 9: 333-339.

Hashemi M, Moazeni-Roodi AK, Fazaeli A, Sandoughi M, et al. (2010b). The L55M polymorphism of paraoxonase-1 is a risk factor for rheumatoid arthritis. Genet. Mol. Res. 9: 1735-1741.

Hashemi M, Hoseini H, Yaghmaei P, Moazeni-Roodi A, et al. (2011a). Association of polymorphisms in glutamatecysteine ligase catalytic subunit and microsomal triglyceride transfer protein genes with nonalcoholic fatty liver disease. DNA Cell Biol. 30: 569-575.

Hashemi M, Sharifi-Mood B, Nezamdoost M, Moazeni-Roodi A, et al. (2011b). Functional polymorphism of interferongamma (IFN-gamma) gene $+874 \mathrm{~T} / \mathrm{A}$ polymorphism is associated with pulmonary tuberculosis in Zahedan, Southeast Iran. Prague Med. Rep. 112: 38-43.

Hermiston ML, Xu Z, Majeti R and Weiss A (2002). Reciprocal regulation of lymphocyte activation by tyrosine kinases and phosphatases. J. Clin. Invest. 109: 9-14.

Hill RJ, Zozulya S, Lu YL, Ward K, et al. (2002). The lymphoid protein tyrosine phosphatase Lyp interacts with the adaptor molecule Grb2 and functions as a negative regulator of T-cell activation. Exp. Hematol. 30: 237-244.

Hinks A, Worthington J and Thomson W (2006). The association of PTPN22 with rheumatoid arthritis and juvenile idiopathic arthritis. Rheumatology 45: 365-368.

Ikegami H, Kawabata Y, Noso S, Fujisawa T, et al. (2007). Genetics of type 1 diabetes in Asian and Caucasian populations. Diabetes Res. Clin. Pract. 77 (Suppl 1): S116-S121.

Jagiello P, Aries P, Arning L, Wagenleiter SE, et al. (2005). The PTPN22 620W allele is a risk factor for Wegener's granulomatosis. Arthritis Rheum. 52: 4039-4043.

Lamsyah H, Rueda B, Baassi L, Elaouad R, et al. (2009). Association of PTPN22 gene functional variants with development of pulmonary tuberculosis in Moroccan population. Tissue Antigens 74: 228-232.

Lee YH, Rho YH, Choi SJ, Ji JD, et al. (2007). The PTPN22 C1858T functional polymorphism and autoimmune diseases - a meta-analysis. Rheumatology 46: 49-56.

Mori M, Yamada R, Kobayashi K, Kawaida R, et al. (2005). Ethnic differences in allele frequency of autoimmune-diseaseassociated SNPs. J. Hum. Genet. 50: 264-266.

Mustelin T, Brockdorff J, Rudbeck L, Gjorloff-Wingren A, et al. (1999). The next wave: protein tyrosine phosphatases enter T cell antigen receptor signalling. Cell Signal. 11: 637-650.

Mustelin T, Abraham RT, Rudd CE, Alonso A, et al. (2002). Protein tyrosine phosphorylation in T cell signaling. Front Biosci. 7: d918-d969.

Naderi M, Hashemi M, Kouhpayeh H and Ahmadi R (2009). The status of serum procalcitonin in pulmonary tuberculosis and nontuberculosis pulmonary disease. J. Pak. Med. Assoc. 59: 647-648.

Naderi M, Hashemi M, Mehdizadeh A and Mehrabifar H (2010). Serum adenosine deaminase activity and total antioxidant capacity of plasma in pulmonary tuberculosis and non-tuberculosis pulmonary disease. Turk. J. Med. Sci. 40: 701-706.

North RJ and Jung YJ (2004). Immunity to tuberculosis. Annu. Rev. Immunol. 22: 599-623.

Orozco G, Sanchez E, Gonzalez-Gay MA, Lopez-Nevot MA, et al. (2005). Association of a functional single-nucleotide polymorphism of PTPN22, encoding lymphoid protein phosphatase, with rheumatoid arthritis and systemic lupus erythematosus. Arthritis Rheum. 52: 219-224.

Porter JD and McAdam KP (1994). The re-emergence of tuberculosis. Annu. Rev. Public Health 15: 303-323.

Qu HQ, Fisher-Hoch SP and McCormick JB (2011). Molecular immunity to mycobacteria: knowledge from the mutation and phenotype spectrum analysis of Mendelian susceptibility to mycobacterial diseases. Int. J. Infect. Dis. 15: e305-e313.

Reddy MV, Johansson M, Sturfelt G, Jonsen A, et al. (2005). The R620W C/T polymorphism of the gene PTPN22 is associated with SLE independently of the association of PDCD1. Genes Immun. 6: 658-662.

Seldin MF, Shigeta R, Laiho K, Li H, et al. (2005). Finnish case-control and family studies support PTPN22 R620W polymorphism as a risk factor in rheumatoid arthritis, but suggest only minimal or no effect in juvenile idiopathic arthritis. Genes Immun. 6: 720-722.

Veillette A, Latour S and Davidson D (2002). Negative regulation of immunoreceptor signaling. Annu. Rev. Immunol. 20: 669-707.

Wipff J, Allanore Y, Kahan A, Meyer O, et al. (2006). Lack of association between the protein tyrosine phosphatase nonreceptor 22 (PTPN22)*620W allele and systemic sclerosis in the French Caucasian population. Ann. Rheum. Dis. 65: $1230-1232$

Zhang ZH, Chen F, Zhang XL, Jin Y, et al. (2008). PTPN22 allele polymorphisms in 15 Chinese populations. Int. J. Immunogenet. 35: 433-437. 